\title{
HISTOLOGICAL SCORING SYSTEMS IN ULCERATIVE COLITIS PATIENTS: A ROUTINE PRACTICE PERSPECTIVE
}

\author{
Anamaria CURTE ${ }^{1 凶}$, Gabriel BECHEANU ${ }^{2,3}$, Florin ANDREI ${ }^{1,2}$, Catalina NICOLAE ${ }^{1}$, \\ Madalina CHIVU $^{1}$, Cristian TIERANU ${ }^{4}$, Maria SAJIN 5,6 \\ ${ }^{1}$ Department of Pathology, "Elias" University Emergency Hospital, Bucharest, Romania \\ ${ }^{2}$ Department of Pathology, "Victor Babes" National Institute of Pathology, Bucharest, Romania \\ 3 "Carol Davila“ University of Medicine and Pharmacy, Bucharest, Romania \\ ${ }^{4}$ Department of Gastroenterology, "Elias“ University Emergency Hospital, Bucharest, Romania \\ ${ }^{5}$ Department of Pathology, University Emergency Hospital Bucharest, Romania \\ ${ }^{6}$ „Carol Davila“ University of Medicine and Pharmacy, Bucharest, Romania
}

\author{
Received 15 Jan 2020, Accepted 16 Febr 2020 \\ https://doi.org/10.31688/ABMU.2020.55.1.07
}

\section{Abstract}

Introduction. Histological healing has become a therapeutic goal in patients with ulcerative colitis. However, a consensus on its precise definition has not been reached yet. A large number of complex histological scoring systems for ulcerative colitis are available in literature making standardization a complicated issue. The objective of the study was to identify a histological scoring system that is adequate for routine practice and thus contributes to standardization of histological reporting of inflammation activity in ulcerative colitis. Materials and methods. We retrospectively reviewed and scored $64 \mathrm{H \& E}$ stained slides using Nancy index (NI), Geboes score (GS) and Robarts Histopathology Index (RHI). The level of inter-rater and intra-rater agreement, time needed for scoring per slide, and correlation between the histological scores and Mayo endoscopic score were further analysed statistically.

Results. The inter-rater agreement was very good for NI (kappa $=0.861)$ and GS (kappa $=0.820)$, and moderate for RHI (kappa $=0.592), p<0.005$. The intra-rater agreement was very good for NI (kappa=0.973), GS

\section{Résumé}

Systèmes de grading histologique chez les patients atteints de colite ulcéreuse: une perspective pratique de routine

Introduction. La guérison histologique est devenue un objectif thérapeutique chez les patients atteints de colite ulcéreuse. Cependant, un consensus sur sa définition précise n'a pas encore été atteint. Un grand nombre de systèmes de grading histologique complexes pour la colite ulcéreuse sont disponibles dans la littérature, ce qui rend la standardisation compliquée.

L'objectif de l'étude était d'identifier un système de grading histologique adapté à la pratique de routine et de contribuer ainsi à la standardisation du rapport histologique de l'activité inflammatoire dans la colite ulcéreuse.

Matériaux et méthodes. Nous avons examiné rétrospectivement et noté 64 lames colorées H\&E en utilisant l'index de Nancy (NI), le score Geboes (GS) et l'indice histopathologique Robarts (RHI) par trois pathologistes indépendants. Le niveau d'accord 
(kappa=0.942), and RHI (kappa=0.892), p<0.005. NI needed the least time to rate (average of $72.06 \mathrm{~s}$ / slide), followed by GS (77.55s/slide) and RHI (92.67s/ slide). The differences were statistically significant by Friedman's test. All scoring systems correlated well with Mayo score.

Conclusions. Nancy index and Geboes score appeared as most suitable for assessment of inflammation in ulcerative colitis in routine practice. $\mathrm{NI}$ is fast and has a simple approach. Geboes score is more complex. Though simple scores are more likely to be accepted in routine practice, complex scoring systems could be more appropriate for evaluation of histological healing and for research purposes.

Keywords: ulcerative colitis, Nancy index, Geboes score, Robarts Histopathology Index, histological scoring systems.

\author{
List of abbreviations \\ $\mathrm{UC}=$ ulcerative colitis \\ IBD = inflammatory bowel disease \\ $\mathrm{H} \& \mathrm{E}=$ haematoxilin and eosin \\ $\mathrm{NI}=$ Nancy index \\ GS $=$ Geboes score \\ RHI = Robarts Histopathology Index
}

\section{INTRODUCTION}

Mucosal healing in patients with inflammatory bowel disease (IBD) is a concept that has evolved greatly in the past years due to the introduction of biological therapy which led to the possibility of achieving clinical and endoscopic remission.

However, endoscopic remission does not always imply histological healing. It has been suggested that histological healing should be a therapeutic end-point at least in patients with ulcerative colitis $(\mathrm{UC})^{1}$. This hypothesis has been backed recently by several studies that have shown that histological healing predicts sustained clinical remission and risk of relapse $e^{2.5}$. Nevertheless, a consensus on a precise definition of histological healing has not been reached yet and lack of standardization regarding scoring inflammation, both in routine colonic biopsy reporting and in clinical research, is one of the main obstacles.

The objective of the Study was to assess histological scoring systems for ulcerative colitis available in the literature from a clinical use perspective, in order to identify one that could be applied in a reproducible, standardized manner and that is adequate for routine practice in the department of general inter-évaluateurs et intra-évaluateurs, le temps nécessaire pour le grading par lame et la corrélation entre les scores histologiques et le score endoscopique de Mayo ont ensuite été analysés statistiquement.

Résultats. L'accord inter-évaluateurs était très bon pour NI (kappa $=0,861)$ et GS (kappa $=0,820)$, et modéré pour RHI (kappa $=0,592), p<0,005$. Laccord intra-rater était très bon pour NI (kappa $=0,973)$, GS $($ kappa $=0,942)$ et RHI (kappa $=0,892), p<0,005 . \mathrm{NI}$ a eu le moindre temps pour noter (moyenne de 72,06s/ lame), suivi de GS (77,55s/lame) et RHI (92,67s/lame). Les différences étaient statistiquement significatives selon le test de Friedman. Tous les systèmes de grading étaient bien corrélés avec le score de Mayo.

Conclusions. L'indice de Nancy et le score de Geboes sont apparus comme les plus appropriés pour l'évaluation de routine de l'inflammation dans la colite ulcéreuse. Bien que les scores simples soient plus susceptibles d'être acceptés dans la pratique courante, des systèmes de notation complexes pourraient être plus appropriés pour l'évaluation de la guérison histologique et à des fins de recherche.

Mots-clés: colite ulcéreuse, l'indice de Nancy, système de notation Geboes, l'indice histopathologique Robarts, systèmes de grading histologique.

pathology and thus to contribute to standardization of histological reporting in ulcerative colitis.

\section{Material AND Methods}

We retrospectively reviewed the cases diagnosed with ulcerative colitis between January 2017-December 2019 in the Pathology Department of "Elias" University Emergency Hospital, Bucharest, Romania. We found $64 \mathrm{H \& E}$ stained slides from 46 cases. The slides were blinded and scored by three independent pathologists using Nancy index, Geboes score and Robarts histopathology index, at different times for each score. The scores were selected from the large number of scoring systems available in the current literature by the following criteria: validation in published studies, ease of use and by being more familiar to the observers. Time needed per slide examination was measured in seconds and recorded. Cohen's kappa test was performed for evaluation of the level of inter-rater and intra-rater agreement. Comparison of timing for each score was made using Friedman's test. Spearman's test was used for assessing the correlation between the histological scores and Mayo endoscopic score. All statistical tests were performed using SPSS 20 software (Chicago). 
Table 1. Correspondence of scores - Nancy index and Robarts Histopathology Index

\begin{tabular}{|c|c|c|c|c|c|c|c|c|c|c|c|c|c|}
\hline & & & \multicolumn{10}{|c|}{ Robarts Histopathology Index } & \multirow[t]{2}{*}{ Total } \\
\hline & & & 1 & 3 & 5 & 6 & 7 & 8 & 9 & 10 & 11 & 12 & \\
\hline \multirow{16}{*}{$\begin{array}{l}\text { Nancy } \\
\text { index }\end{array}$} & \multirow{4}{*}{0} & $\begin{array}{l}\text { Number of } \\
\text { slides }\end{array}$ & 1 & 0 & 0 & 0 & 0 & 0 & 0 & 0 & 0 & 0 & 1 \\
\hline & & \% within NI & $100 \%$ & & & & & & & & & & $100 \%$ \\
\hline & & \% within RHI & $100 \%$ & & & & & & & & & & $1.6 \%$ \\
\hline & & $\%$ of Total & $1.6 \%$ & & & & & & & & & & $1.6 \%$ \\
\hline & \multirow{4}{*}{2} & $\begin{array}{c}\text { Number of } \\
\text { slides }\end{array}$ & 0 & 4 & 3 & 4 & 2 & 0 & 0 & 0 & 0 & 0 & 13 \\
\hline & & \% within NI & & $30.8 \%$ & $23.1 \%$ & $30.8 \%$ & $15.4 \%$ & & & & & & $100 \%$ \\
\hline & & \% within RHI & & $100 \%$ & $100 \%$ & $80.0 \%$ & $40.0 \%$ & & & & & & $20.3 \%$ \\
\hline & & $\%$ of Total & & $6.2 \%$ & $4.7 \%$ & $6.2 \%$ & $3.1 \%$ & & & & & & $20.3 \%$ \\
\hline & \multirow{4}{*}{3} & $\begin{array}{l}\text { Number of } \\
\text { slides }\end{array}$ & 0 & 0 & 0 & 1 & 3 & 4 & 7 & 11 & 10 & 0 & 36 \\
\hline & & \% within NI & & & & $2.8 \%$ & $8.3 \%$ & $11.1 \%$ & $19.4 \%$ & $30.6 \%$ & $27.8 \%$ & & $100 \%$ \\
\hline & & \% within RHI & & & & $20.0 \%$ & $60.0 \%$ & $100 \%$ & $100 \%$ & $91.7 \%$ & $83.3 \%$ & & $56.2 \%$ \\
\hline & & $\%$ of Total & & & & $1.6 \%$ & $4.7 \%$ & $6.2 \%$ & $10.9 \%$ & $17.2 \%$ & $15.6 \%$ & & $56.2 \%$ \\
\hline & \multirow{4}{*}{4} & $\begin{array}{c}\text { Number of } \\
\text { slides }\end{array}$ & 0 & 0 & 0 & 0 & 0 & 0 & 0 & 1 & 2 & 11 & 14 \\
\hline & & \% within NI & & & & & & & & $7.1 \%$ & $14.3 \%$ & $78.6 \%$ & $100 \%$ \\
\hline & & \% within RHI & & & & & & & & $8.3 \%$ & $16.7 \%$ & $100 \%$ & $21.9 \%$ \\
\hline & & $\%$ of Total & & & & & & & & $1.6 \%$ & $3.1 \%$ & $17.2 \%$ & $21.9 \%$ \\
\hline \multirow{4}{*}{ Total } & & $\begin{array}{l}\text { Number of } \\
\text { slides }\end{array}$ & 1 & 4 & 3 & 5 & 5 & 4 & 7 & 12 & 12 & 11 & 64 \\
\hline & & \% within NI & $1.6 \%$ & $6.2 \%$ & $4.7 \%$ & $7.8 \%$ & $7.8 \%$ & $6.2 \%$ & $10.9 \%$ & $18.8 \%$ & $18.8 \%$ & $17.2 \%$ & $100 \%$ \\
\hline & & \% within RHI & $100 \%$ & $100 \%$ & $100 \%$ & $100 \%$ & $100 \%$ & $100 \%$ & $100 \%$ & $100 \%$ & $100 \%$ & $100 \%$ & $100 \%$ \\
\hline & & $\%$ of Total & $1.6 \%$ & $6.2 \%$ & $4.7 \%$ & $7.8 \%$ & $7.8 \%$ & $6.2 \%$ & $10.9 \%$ & $18.8 \%$ & $18.8 \%$ & $17.2 \%$ & $100 \%$ \\
\hline
\end{tabular}

NI - Nancy Index

RHI - Robarts Histopathology Index

\section{Results}

We evaluated 64 histological slides from 46 cases, 29 men and 17 women, with a mean age of 38.7 years. Thirty-eight patients were under treatment with 5-aminosalicylates, corticosteroids, azathioprine and/or biologic therapy. Eight patients stated they were not taking medication. Most cases presented with pancolitis (50\%), 36.95\% of cases had left-sided colitis, $10.86 \%$ had proctitis and one patient showed no endoscopic abnormalitites.

Correspondence of scoring categories for Nancy index, Geboes score and Robarts Histopathology Index is shown in Tables 1 and 2. Analysis of biopsy scoring in our study shows there is a general concordance between the different scoring systems. An overlap between subcategories in GS and categories in Nancy index is observed especially when erosion is present. For example, presence of mild erosion on one slide was scored as 2 in Nancy index, corresponding to mildly active inflammation, but was paradoxically assigned to grade 5 in Geboes score (5.2 subcategory: probable erosion - focally striped), because in the latter scoring system grade 5 denominates erosion (and ulceration), regardless of its extension.

When ulceration was present, assignment to the corresponding score was done reliably in Nancy index and Geboes score. However, when using RHI, slides showing ulceration were scored from 10 to 12 points, as this histological parameter does not necessarily correspond to a maximum scoring category.

At the other end of the scoring scale, a mild increase of the chronic inflammatory infiltrate was assigned to score 0 in Nancy index, 1.1 subcategory in Geboes score, and 1 point in RHI.

The interrater agreement, measured by mean Cohen's kappa, was very good for Nancy index (kap$\mathrm{pa}=0.861)$ and for Geboes score $(\mathrm{kappa}=0.820)$, and moderate for RHI (kappa= 0.592), p values $<0.005$ (Table 3).

The intrarater agreement was very good with a kappa value of 0.973 for Nancy index, 0.942 for Geboes score, and 0.892 for RHI ( $<<0.005)$ (Table 3). 
Table 2. Correspondence of scores - Nancy index and Geboes score

\begin{tabular}{|c|c|c|c|c|c|c|c|c|c|c|c|c|}
\hline & & & \multicolumn{9}{|c|}{ Geboes score } & \multirow[t]{2}{*}{ Total } \\
\hline & & & 1.1 & 3.1 & 3.2 & 4.1 & 4.2 & 5.1 & 5.2 & 5.3 & 5.4 & \\
\hline \multirow{16}{*}{$\begin{array}{l}\text { Nancy } \\
\text { index }\end{array}$} & \multirow{4}{*}{0} & Number of slides & 1 & 0 & 0 & 0 & 0 & 0 & 0 & 0 & 0 & 1 \\
\hline & & \% within NI & $100 \%$ & & & & & & & & & $100 \%$ \\
\hline & & \% within GS & $100 \%$ & & & & & & & & & $1.6 \%$ \\
\hline & & $\%$ of Total & $1.6 \%$ & & & & & & & & & $1.6 \%$ \\
\hline & \multirow{4}{*}{2} & Number of slides & 0 & 7 & 4 & 0 & 1 & 0 & 1 & 0 & 0 & 13 \\
\hline & & \% within NI & & $53.8 \%$ & $30.8 \%$ & & $7.7 \%$ & & $7.7 \%$ & & & $100 \%$ \\
\hline & & \% within GS & & $100 \%$ & $100 \%$ & & $50.0 \%$ & & $14.3 \%$ & & & $20.3 \%$ \\
\hline & & $\%$ of Total & & $10.9 \%$ & $6.2 \%$ & & $1.6 \%$ & & $1.6 \%$ & & & $20.3 \%$ \\
\hline & \multirow{4}{*}{3} & Number of slides & 0 & 0 & 0 & 2 & 1 & 7 & 6 & 20 & 0 & 36 \\
\hline & & \% within NI & & & & $5.6 \%$ & $2.8 \%$ & $19.4 \%$ & $16.7 \%$ & $55.6 \%$ & & $100 \%$ \\
\hline & & $\begin{array}{c}\text { \% within Geboes } \\
\text { score }\end{array}$ & & & & $100 \%$ & $50.0 \%$ & $100 \%$ & $85.7 \%$ & $95.2 \%$ & & $56.2 \%$ \\
\hline & & $\%$ of Total & & & & $3.1 \%$ & $1.6 \%$ & $10.9 \%$ & $9.4 \%$ & $31.2 \%$ & $0.0 \%$ & $56.2 \%$ \\
\hline & \multirow{4}{*}{4} & Number of slides & 0 & 0 & 0 & 0 & 0 & 0 & 0 & 1 & 13 & 14 \\
\hline & & \% within NI & & & & & & & & $7.1 \%$ & $92.9 \%$ & $100 \%$ \\
\hline & & \% within GS & & & & & & & & $4.8 \%$ & $100 \%$ & $21.9 \%$ \\
\hline & & $\%$ of Total & & & & & & & & $1.6 \%$ & $20.3 \%$ & $21.9 \%$ \\
\hline \multirow{4}{*}{\multicolumn{2}{|c|}{ Total }} & Number of slides & 1 & 7 & 4 & 2 & 2 & 7 & 7 & 21 & 13 & 64 \\
\hline & & \% within NI & $1.6 \%$ & $10.9 \%$ & $6.2 \%$ & $3.1 \%$ & $3.1 \%$ & $10.9 \%$ & $10.9 \%$ & $32.8 \%$ & $20.3 \%$ & $100 \%$ \\
\hline & & \% within GS & $100 \%$ & $100 \%$ & $100 \%$ & $100 \%$ & $100 \%$ & $100 \%$ & $100 \%$ & $100 \%$ & $100 \%$ & $100 \%$ \\
\hline & & $\%$ of Total & $1.6 \%$ & $10.9 \%$ & $6.2 \%$ & $3.1 \%$ & $3.1 \%$ & $10.9 \%$ & $10.9 \%$ & $32.8 \%$ & $20.3 \%$ & $100 \%$ \\
\hline
\end{tabular}

GS - Geboes score; NI - Nancy Index

Table 3. Interobserver and intraobserver agreement on Nancy index, Geboes score and Robarts histopathology index

\begin{tabular}{ccccc}
\hline & \multicolumn{5}{c}{ Cohen's Kappa } & p value \\
\hline & Nancy Index & Geboes score & RHI & 0.478 \\
\hline Rater 1 - Rater 2 & 0.895 & 0.845 & 0.604 & $<0.005$ \\
\hline Rater 1 - Rater 3 & 0.870 & 0.789 & 0.696 & $<0.005$ \\
\hline Rater 2 - Rater 3 & 0.818 & 0.826 & 0.592 & $<0.005$ \\
\hline $\begin{array}{c}\text { Interrater } \\
\text { Mean Cohen's Kappa }\end{array}$ & 0.861 & 0.820 & 0.892 & $<0.005$ \\
\hline Intrarater Cohen's Kappa & 0.973 & 0.942 & & \\
\hline
\end{tabular}

Table 4. Time necessary for scoring (in seconds)

\begin{tabular}{cccccc}
\hline \multirow{2}{*}{ Scoring system } & \multirow{2}{*}{$\begin{array}{l}\text { Mean time } \\
{[\mathrm{min}, \max ]}\end{array}$} & Standard Deviation & \multicolumn{3}{c}{ Percentiles } \\
\cline { 4 - 6 } & $72.06 \mathrm{~s}[43,111]$ & 17.232 & $61.00 \mathrm{~s}$ & $68.50 \mathrm{~s}$ & $80.00 \mathrm{~s}$ \\
\hline Nancy index & $77.55 \mathrm{~s}[33,137]$ & 18.119 & $65.00 \mathrm{~s}$ & $72.50 \mathrm{~s}$ & $85.00 \mathrm{~s}$ \\
\hline Geboes score & $92.67 \mathrm{~s}[45,142]$ & 20.809 & $82.00 \mathrm{~s}$ & $90.00 \mathrm{~s}$ & $102.75 \mathrm{~s}$ \\
\hline Robarts Histopathology Index &
\end{tabular}

Table 5. Correlation of Mayo endoscopic partial score and Nancy index, Geboes score and Robarts histopathology index

\begin{tabular}{ccc}
\hline Histological scores & Spearman's correlation coefficient & p value \\
\hline Nancy index & 0.412 & 0.004 \\
\hline Geboes score subcategories & 0.469 & 0.001 \\
\hline Robarts Histopathology Index & 0.357 & 0.015 \\
\hline
\end{tabular}

$\mathrm{NI}=$ Nancy Index; No. of slides $=$ number of slides 


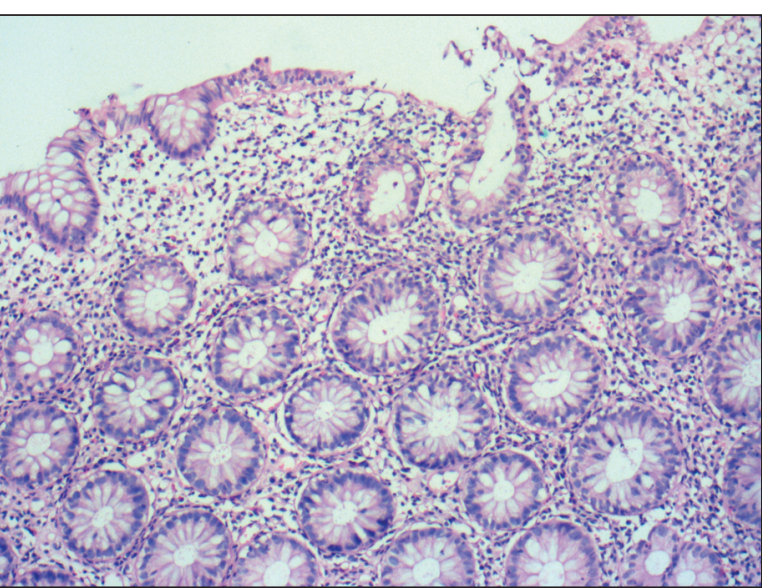

Figure 1. Chronic colitis with mild activity (Nancy 2, Geboes 3.1, RHI 3). Mild increase of chronic inflammatory infiltrate and focal cryptitis.

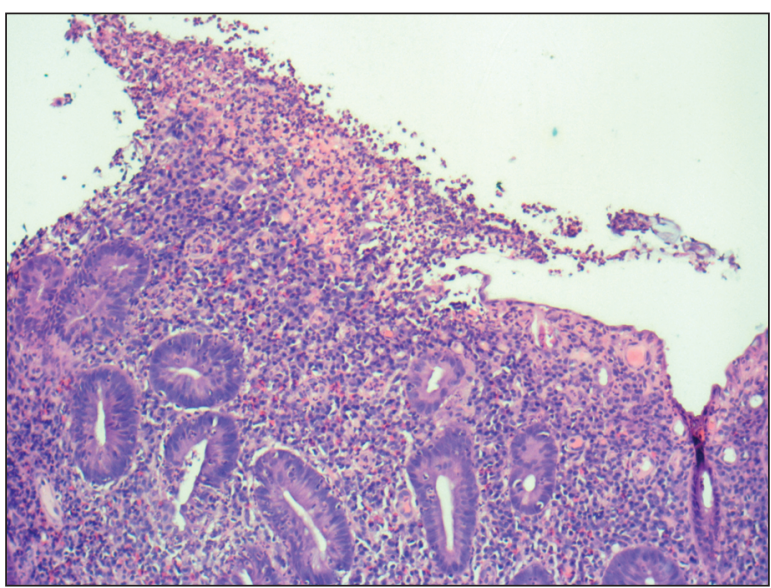

Figure 3. Chronic colitis with extensive erosion (Nancy 3, Geboes 5.3, RHI 10). Chronic colitis showing extensive erosion, crypt distorsion, crypt microabcesses and markedly increased chronic and acute inflammatory infiltrate in lamina propria.

The Nancy index needed the least time to rate (an average of 72.06 seconds per slide), followed by Geboes score (average 77.55 seconds) and RHI (average 92.67 seconds). The differences were statistically significant by Friedman's test $\left(\chi^{2}(2)=67.881\right.$, $\mathrm{p}<0.005$ ) (Table 4).

Time necessary for scoring did not seem to be dependent on the number of biopsies or scoring category. Nevertheless, when obvious ulceration was present, the time for assessing a slide was reduced.

All scoring systems correlated well with Mayo endoscopic partial score by Spearman's correlation coefficient, $p<0.05$. For this correlation test, in cases with multiple slides, the highest score per case was used (Table 5).

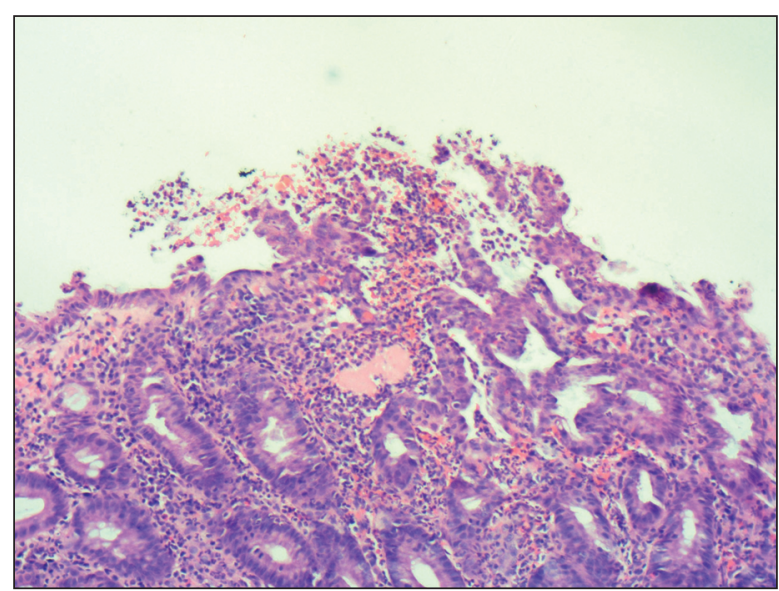

Figure 2. Chronic colitis with erosion (Nancy 3, Geboes 5.3, RHI 9). Chronic colitis showing surface erosion, crypt distorsion, cryptitis and moderately increased chronic and acute inflammatory infiltrate in lamina propria.

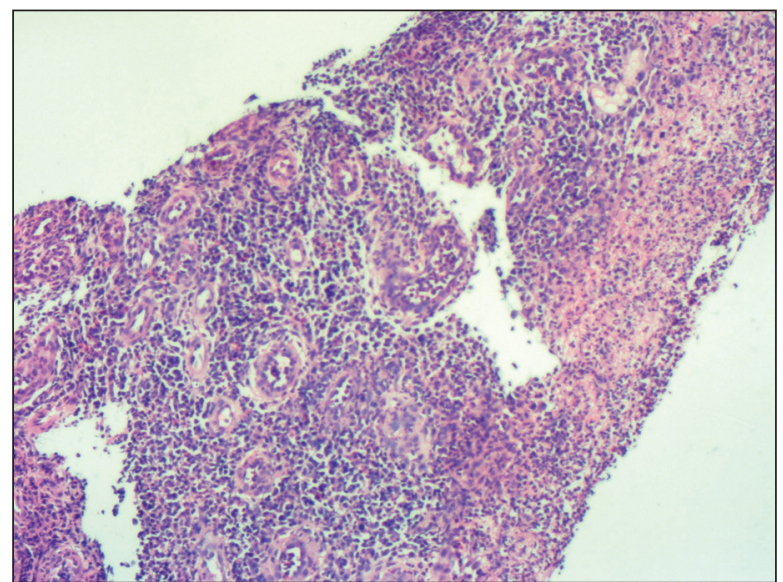

Figure 4. Chronic colitis with ulceration (Nancy 4, Geboes 5.4, RHI 12). Granulation tissue, acute and chronic inflammatory infiltrate and fibrin deposition suggesting the presence of ulceration.

\section{Discussion}

This study focuses on histological scoring systems from a routine work perspective and aimes at contributing to standardization of reporting inflammation status in ulcerative colitis. A simple approach and reduced time for assessment are important factors when using a scoring system in practice. Most scoring systems are complex and therefore difficult to integrate in daily work.

At least 22 scoring systems have been proposed for ulcerative colitis, but until present there is no consensus on a standard score for histological inflammation evaluation and reporting. Of the numerous histological scoring systems that have been proposed for IBD evaluation, only a few have been validated. 
More to that, it is the opinion of gastrointestinal pathology experts ${ }^{6}$ that, due to their complexity, they are generally more suited for scientific purposes and are difficult to use in routine practice. In some scores, particular aspects of the scoring process imply a high level of subjectivity and they usually take considerable time for assessing.

However, a few authors have recently proposed either new simple scoring systems or simplified versions of already published scores.

Nancy histological index was developed by a group led by Marchal-Bressenot ${ }^{7}$. The group proposed a three descriptor system with four grades, in which presence of ulceration is the first element to be looked for ${ }^{8}$. If not present, assessment should move forward to evaluation of acute and chronic inflammation. It is a simple, easy to use, validated scoring system and it does not absolutely require orientation of the biopsy specimens.

Villanacci ${ }^{6}$ also aimed at developing a simple, less time-consuming scoring system, which would be more appropriate for routine practice. For assessment it is essential to be provided by the endoscopist with two samples from each colonic segment and terminal ileum. The authors also recommend that the biopsies are oriented on cellulose filters. This validated score requires assessment of the presence or absence of three histological parameters (crypt abcesses, erosions/ulceratios and neutrophils in lamina propria) and their locations on the ileon and colon segment.

The score proposed by Geboes 9 is a very widely used 6 grade scoring system in studies of ulcerative colitis, is rather complex and complicated for routine clinical use. It also implies some degree of subjectivity in assessing the amount of active inflammation and there are many subcategories for evaluating the presence of erosions/ulceration. Recently, Jauregui-Amezaga, together with a group including Geboes $^{10}$ developed a simplified version of the system which still has to undergo full validation.

Aiming to reduce interrater subjectivity, a group of authors ${ }^{11}$ developed the Robarts Histopatology Index, trying to simplify the Geboes score. Four histological criteria are to be assessed and assigned a 0 to 3 score (chronic inflammatory infiltrate, lamina propria neutrophils, neutrophils in epithelium and erosion/ulceration), with a total score of maximum 12 points.

We selected for our study three scoring systems which are most widely used in the literature. All the scoring systems had good inter and intrarater level of agreement and correlated well with Mayo score. The best inter and intraobserver agreement was reached with Nancy index, closely followed by Geboes score. In our study, time needed for assessing the slides was significantly less for Nancy and Geboes scoring systems than for RHI, which is more laborious as each parameter must be scored and then all the values summed. Even if the structure of RHI resembles Geboes's score, we found it to be more unhandy and time consuming. Time for assessing the slides was reduced for Nancy and Geboes scores when ulceration was present, and was not significantly influenced by the number of fragments per slide.

Time needed for assessment by different scoring systems was also reported by Villanacci et $\mathrm{al}^{6}$. However, in that study, all biopsies from various colon segments from a single patient were on the same slide, therefore, the time reported for evaluation was longer. Therefore, the times recorded in the study mentioned above and our study cannot be compared adequately.

Although Geboes score is at the beginning more difficult to use and adapt to than Nancy index because of its complex structure, after familiarisation we found it rather similar to the latter for practical use.

Recommendations for assessing histological activity in $\mathrm{UC}$, as proposed by various experts and the ECCO guidelines ${ }^{6,7,12,13}$ include examination of 2 properly fixed biopsies sampled from each segment of colon, including rectum and terminal ileum, especially from the most affected areas (particularly ulcers). This sampling pattern would increase the likeliness to adequately assess the presence and severity of lesions as UC may have discontinuous appearance as consequence of natural evolution or as effect of treatment ${ }^{1}$. Orientation of specimens is mandatory, ideally on mounting material (cellulose filter). H\&E slides should have at least two levels with several sections of the fragments. The grade of activity should be established on the fragment showing the most severe features. However, to our knowledge, these recommendations for biopsy sampling are still not widespread in gastroenterology and general pathology departments. The reasons for this are most likely the following: biopsies are taken by clinicians from the site of injury, if found; biopsies from normal appearing mucosa are not taken routinely; colonoscopy is not performed if patients are in clinical remission and surrogate inflammatory markers such as fecal calprotectin or lactoferrin are negative on follow-up.

It is generally acknowledged that the characteristic histological features of ulcerative colitis are altered crypt architecture (crypt branching, distorsion, loss of crypts, irregularity of the mucosal surface) and basal plasmacytosis and transmucosal inflammatory infiltrate ${ }^{14}$. Villanacci ${ }^{1}$ observed that basal plasmacytosis and intermingled eosinophils may help in initial diagnosis of IBD as well. There generally is consensus and 
good interobserver agreement regarding evaluation of active disease, represented by neutrophils in crypt epithelium, and formation of crypt abcesses. Elements diagnostic for quiescent disease are absence of neutrophils in lamina propria, though reminiscents of chronic inflammation may still be found, along with eosinophils ${ }^{6,15}$.

Ideally, histological healing is represented by reversal of all pathological features and restitutio ad integrum i.e. resolution of crypt abnormalities and inflammation ${ }^{16}$. However, studies focused on evaluation of various therapies have not thoroughly reported the histological features that were labeled as histological healing or remission, but have only remarked the decrease of the histological score. More to that, similar to studies that evaluated endoscopical mucosal healing ${ }^{14}$, the terms histological healing and remission are frequently used interchangeably, although they do not necessarily share a common histological appearance and meaning.

Recent studies ${ }^{2-5,17,18}$ have shown that histological healing, rather than endoscopic healing alone, is more predictive for clinical remission of patients with ulcerative colitis. However, authors have used in their studies various scoring systems and terms, such as "histologic normalization“, „histological remission“. There still is a lack of standardization of histological approach in IBD, therefore, it is important to reach a consensus on a precise and standardized definition of histological healing and to identify a scoring systems adequate for routine use. In our experience, Nancy index is the most practical scoring system, as it has a simple and quick algorithm. However, Geboes score, after familiarization and training, is similar in terms of easiness of use and, in addition, its subcategories correspond to a more precise histological description.

It appears that up to $40 \%$ of the patients with ulcerative colitis reach complete normalisation of the biopsies $^{1,4,17,19}$. None of our cases presented complete histologic normalization and only one case showed mild chronic inactive inflammation (Nancy 0 , Geboes 1.1; RHI 1, Mayo 0). In most patients, remission is translated histologically as persistence of architectural alterations (decrease in crypt density, branching and shortening), reduced epithelial regeneration, and variable mucosal inflammatory infiltrates (either mixed polymorphous and lympho-plasmacytic hypercellularity, or reduced/absent neutrophils, decreased chronic inflammation and basal plasmacytosis $)^{11}$. Eosinophils may play an important role in defining remission, because, as opposed to neutrophils, they appear to not decrease, and their persistence, along with basal plasmacytosis, seems to increase the risk of relapse ${ }^{19,20}$. The presence of eosinophils is scored separately only in the Geboes score. It is still a controversy if the absence of basal plasmacytosis should be regarded as mandatory for histological healing.

\section{Conclusions}

Among the scores evaluated, Nancy index and Geboes score appeared as most suitable for routine practice when scoring inflammation in ulcerative colitis. Nancy index has a simple algorithm and showed the most reduced time for assessment. Geboes score is more complex, but after training the time needed for assessment was rather close to Nancy index. A very good interobserver and intraobserver agreement level was observed for both scoring systems. However, Robarts Histopathology Index showed a lower interobserver level of agreement, was more laborious and time-consuming.

Though simple scores are more likely to be accepted in routine practice, more complex scoring systems could be more appropriate for evaluation of histological healing, and could also include new histological parameters to better predict the clinical evolution.

\section{Author contributions}

Conceptualization, A.C., M.S., and G.B.; methodology, A.C.; software, A.C; formal analysis, A.C., M.C., C.N., and F.A.; resources, A.C. and F.A.; data curation, M.C., C.N., F.A., and C.T.; writing-original draft preparation, A.C.; writing- A.C., M.S., M.C., C.N., and C.T.; supervision, G.B. and M.S. All the authors have read and agreed with the final version of the article.

\section{Compliance with Ethics Requirements:}

"The authors declare no conflict of interest regarding this article"

"The authors declare that all the procedures and experiments of this study respect the ethical standards in the Helsinki Declaration of 1975, as revised in 2008(5), as well as the national law. Informed consent was obtained from all the patients included in the study"

„This research received no specific grant from any funding agency in the public, commercial, or non-for-profit sectors"

\section{Acknowledgments: none}

\section{References}

1. Villanacci V, Antonelli E, Geboes K, Casella G, Bassotti G. Histological healing in inflammatory bowel disease: A still unfulfilled promise. World Journal of Gastroenterology. 2013;19(7):968-78. 
2. Bryant R V, Burger DC, Delo J, et al. Beyond endoscopic mucosal healing in UC: histological remission better predicts corticosteroid use and hospitalisation over 6 years of follow-up. Gut. 2016;65(3):408-414.

3. Zenlea T, Yee EU, Rosenberg L et al. Histology grade is independently associated with relapse risk in patients with ulcerative colitis in clinical remission: A prospective study. American Journal of Gastroenterology. 2016;111:685-90.

4. Christensen B, Hanauer SB, Erlich J, Kassim O, et al Histologic Normalization Occurs in Ulcerative Colitis and Is Associated With Improved Clinical Outcomes. Clinical Gastroenterology and Hepatology. 2017;15(10):1557-1564.e1.

5. Narang V, Kaur R, Garg B, Mahajan R, Midha V, Sood $\mathrm{N}$. Association of endoscopic and histological remission. Intestinal Research. 2018;16(1):55-61.

6. Villanacci V, Antonelli E, Lanzarotto F, Bozzola A, Cadei M, Bassotti G. Usefulness of different pathological scores to assess healing of the mucosa in inflammatory bowel diseases: a real life study. Science Reports. 2017;7(1):1-8.

7. Marchal-Bressenot A, Salleron J, Boulagnon-Rombi C, et al. Development and validation of the Nancy histological index for UC. Gut. 2017;66(1):43-9.

8. Marchal-Bressenot A, Scherl A, Salleron J, Peyrin-Biroulet L. A practical guide to assess the Nancy histological index for UC. Gut. 2016;65(11):1919-20.

9. Geboes K, Riddell R, Ost A, Jensfelt B, Persson T, Löfberg R. Geboes Score. Gut. 2000;47(3):404-9.

10. Jauregui-Amezaga A, Geerits A, Das Y, et al. A simplified Geboes Score for ulcerative colitis. Journal of Crohns and Colitis. 2017;11(3):305-13.

11. Mosli MH, Feagan BG, Zou G, et al. Development and validation of a histological index for UC. Gut. 2017;66(1):50-8.

12. Magro F, Gionchetti P, Eliakim R, et al. Third European evidence-based consensus on diagnosis and management of ulcerative colitis. Part 1: Definitions, diagnosis, extra-intestinal manifestations, pregnancy, cancer surveillance, surgery, and ileo-anal pouch disorders. Journal of Crohns and Colitis. 2017;11(6):649-70.

13. Pai RK, Jairath V, Vande Casteele N, Rieder F, Parker CE, Lauwers GY. The emerging role of histologic disease activity assessment in ulcerative colitis. Gastrointestinal Endoscopy. 2018;88(6):887-98.

14. Mazzuoli S, Guglielmi FW, Antonelli E, Salemme M, Bassotti G, Villanacci V. Definition and evaluation of mucosal healing in clinical practice. Digestive and Liver Disease. 2013;45(12):969-77.

15. Canavese G, Villanacci V, Antonelli E, et al. Eosinophilia associated basal plasmacytosis: an early and sensitive histologic feature of inflammatory bowel disease. APMIS Journal of Pathology, Microbiology and Immunology. 2017;125(3):179-83.

16. Marchal Bressenot A, Riddell RH, Boulagnon-Rombi C, et al. Review article: The histological assessment of disease activity in ulcerative colitis. Alimentary Pharmacology and Therapeutics 2015;42(8):957-67.

17. Park S, Abdi T, Gentry M, Laine L. Histological disease activity as a predictor of clinical relapse among patients with ulcerative colitis: systematic review and meta-analysis. American Journal of Gastroenterology 2016;111(12):1692-1701.

18. Arijs I, De Hertogh G, Lemmens B, et al. Effect of vedolizumab (anti- $\alpha 4 \beta 7$-integrin) therapy on histological healing and mucosal gene expression in patients with UC. Gut. 2018;67(1):43-52.

19. Bitton A, Peppercorn MA, Antonioli DA, et al. Clinical, biological, and histologic parameters as predictors of relapse in ulcerative colitis. Gastroenterology. 2001;120(1):13-20.

20. Azad S, Sood N, Sood A. Biological and histological parameters as predictors of relapse in ulcerative colitis: a prospective study. Saudi Journal of Gastroenterology. 2011;17(3):194-8. 